\title{
Trading solar energy within the neighborhood: field implementation of a blockchain-based electricity market
}

\author{
Anselma Wörner ${ }^{1 *}$, Arne Meeuw ${ }^{2}$, Liliane Ableitner ${ }^{1}$, Felix Wortmann² ${ }^{2}$ Sandro Schopfer ${ }^{1}$ and \\ Verena Tiefenbeck ${ }^{1}$
}

From The 8th DACH+ Conference on Energy Informatics

Salzburg, Austria. 26-27 September, 2019

\author{
${ }^{*}$ Correspondence: \\ awoerner@ethz.ch \\ ${ }^{1}$ ETH Zürich, Zürich, Switzerland \\ Full list of author information is \\ available at the end of the article
}

\begin{abstract}
Due to environmental and resiliency benefits, distributed energy resources (DER) are a potential solution for meeting future electricity demand, but their integration into centralized power markets on the large scale is challenging. Many practitioners argue that blockchain technology can create new market structures for DER like local peer-topeer energy markets which foster renewable generation. To get an understanding of the status quo of the research on blockchain-based energy exchange, we conducted a systematic literature review on the existing academic articles and industry projects. This article describes the design and technical specifications of the first real

blockchain-based electricity market in Switzerland derived from this literature review and outlines the implementation of this market in the real world. The findings provide valuable guidelines for the integration of DER into future sustainable energy markets.
\end{abstract}

Keywords: Local energy market, Peer-to-peer markets, Blockchain technology, Distributed energy resources, Energy transition, Literature review

\section{Introduction}

As the costs for decentral renewable energy sources (DER), such as wind and solar energy, have been falling considerably, DER have become key levers for transforming the electricity market from a vertical structure into a decentralized, bottom-up landscape and for providing a reliable and sustainable energy supply despite shrinking natural resources (Green and Newman 2017; Hentschel et al. 2018; Morstyn et al. 2018). Together with the liberalization of the electricity market in many countries (Ketter et al. 2013; Vona and Nicolli 2014), technical advances have spurred ambitions to create marketpaces in which renewable energy can be sold from peer to peer in recent years (Andoni et al. 2019; Mengelkamp et al. 2017). Out of the many opportunities for blockchain technology to create new sociotechnical systems and to enable the secure transfer of value, the facilitation of energy exchange is among the most societally relevant. Access to resources and energy security are some of the main public concerns threatening the well-being of our future society and the environment. Many scholars and entrepreneurs are convinced that 
the energy domain could strongly benefit from blockchain technology in the creation of new marketplaces for renewable energy, which may help to ensure future energy supply (Basden and Cottrell 2017; Kastrati and Weissbart 2016). With the general hype of blockchain technology, blockchain-based electricity markets receive increasing attention at policy level (Kastrati and Weissbart 2016) and several start-up companies are putting efforts into creating blockchain solutions for the energy market (Basden and Cottrell 2017; Mengelkamp et al. 2017; Miller et al. 2017; Rivola et al. 2018).

Yet, the decentralization of the energy market is not driven by idealistic views or a technology hype, but for domain-specific, practical reasons. Due to environmental and resiliency benefits, distributed energy resources (DER) are gaining importance as the costs of solar and wind power systems decrease (Halu et al. 2016; Khalilpour and Vassallo 2015; Meeuw et al. 2018). However, the integration of those renewable energy sources into the existing power market has proven to be difficult. Today's power markets are strongly centralized and hierarchical: Utility providers manage electricity generation mostly from central plants according to the expected consumption (Fig. 1, left). Wind and solar power generation, in contrast, is geographically distributed, strongly dependent on local weather conditions, and cannot be simply switched on or off depending on the demand (Ramchurn et al. 2012). Incorporating DER in the market thus increases the complexity of the optimization problem for utility providers and challenges their distribution networks that are not built for bi-directional electricity and information flow. These developments have led to a paradigm shift toward a more decentralized market and spurred ambitions to build peer-to-peer markets (P2P) in which owners of solar panels can sell their production to other consumers on the local low-voltage distribution system (Fig. 1, right). This puts small generation system operators in the focus and creates a competitive environment for distributed generation (Basden and Cottrell 2017).

A decentralized market for DER requires the exchange of electricity between private parties, and blockchain technology is promoted as a suitable information technology to realize this vision. On a blockchain-based market, transactions can be settled without the mediation of a utility company or a financial institution (Mengelkamp et al. 2017). Despite the ongoing hype around blockchain, many critics question the necessity or added value of employing blockchain technology in this context ("Why do you need a blockchain for this?"). Indeed, many existing publications are quite vague about the exact setup of their proposed systems, the market design choices, and in particular the value of the blockchain in this context. There is still little understanding of the economic impact and consumer engagement (Tiefenbeck 2017) in the sociotechnical systems and markets that are being created (Beck et al. 2017; Malinova 2016).

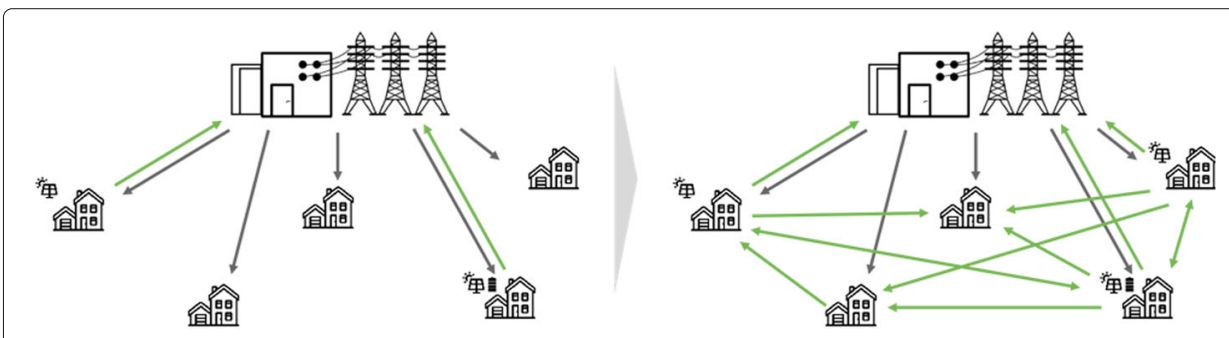

Fig. 1 The electricity market is experiencing a shift to more distributed energy generation and an increasing share of prosumers supplying their own energy 
This article makes two contributions to address this gap: First, we conduct a systematic literature review of both academic and non-academic research to provide an overview of the status quo of blockchain-based energy exchange. Second, based on that knowledge, our team has designed and implemented an instance of a blockchain-based market for solar energy in the real world, in a local municipality in Switzerland. This researchin-progress article presents the design of this system derived from the literature and gives an overview of the market mechanism employed and of the technical specifications. More generally, this article contributes to the design of future electricity markets and opportunities for blockchain technology in this sector.

\section{Related work}

\section{Systematic literature review}

To get an understanding of the status quo of the research on blockchain-based energy exchange, we conducted a systematic literature review on the relevant academic articles as well as the industry projects in the sector. As for the academic literature, we conducted a broad search on Google Scholar and Web of Science as well as a forward and backward search using Google Scholar, in the Spring of 2018. For the keyword search we used the terms "blockchain renewable energy", "blockchain microgrid", and "blockchain electricity trading". While the keyword search on the Web of Science resulted in 22 hits, the Google Scholar search produced over 2000 hits. As suggested by Schlegel et al. (2018), for each of the search terms, only the first 50 results were retained for further analysis to be able to handle the number of results produced by the search engine. We removed duplicates from these results and selected the most relevant articles by reviewing the abstract for relevance to the topic. Filtering for top-ranked outlets (as suggested for example by Notheisen et al. (2017) and Schlegel et al. (2018)) was not done, as this would have excluded most articles due to the very novelty of the area (and given the long duration of publication cycles of many top-ranked outlets). We then pursued with a forward and backward search for the articles retained (Webster and Watson 2002). In the results of the forward and backward search, we scanned again the outlets and abstracts for relevance and selected only the articles that also described peer-to-peer energy exchange. In selecting relevant articles, we explicitly excluded articles examining the energy consumption of different blockchain protocols and their consensus mechanisms, of which many appeared as hits of searches related to blockchain and energy, as these topics are beyond the core of our research scope. The final set of articles retained contained ten articles; Table 1 presents the results.

Beyond the academic research, numerous startups and established businesses are investing in blockchain projects. Multiple companies are currently trying to create decentralized exchanges for electricity using blockchain, some of them in close cooperation with academic scholars (LO3 Energy 2017; Rivola et al. 2018). Given the early stage of the technology, the picture of the status quo of the blockchain use case would be incomplete if we were to focus on academic publications alone, as information on many existing projects so far has only been published in industry whitepapers. Therefore, we also conducted an extensive research on industry projects on blockchain-based peer-topeer exchange of electricity. To that end, we went through the list of companies described in two industry guides on blockchain for the energy sector by Montemayor et al. (2018) and Hasse et al. (2016) and from related posts on the publishing platform Medium.com, 
Table 1 Relevant scientific articles discussing blockchain-based energy markets

\begin{tabular}{|c|c|c|c|c|c|}
\hline Study & Basic Idea & Marketing design & Status & Country & $\begin{array}{l}\text { Blockchain } \\
\text { protocol }\end{array}$ \\
\hline $\begin{array}{l}\text { Mihaylov et al. } \\
\text { (2014); Mihaylov } \\
\text { et al. (Mihaylov et } \\
\text { al. 2014) }\end{array}$ & $\begin{array}{l}\text { P2P trading of NRG } \\
\text { coins within micro- } \\
\text { grid, obtained for } \\
\text { locally produced } \\
\text { energy }\end{array}$ & $\begin{array}{l}\text { Externally fixed } \\
\text { pricing functions }\end{array}$ & $\begin{array}{l}\text { Proof of Concept } \\
\text { (lab-scale } \\
\text { prototype) }\end{array}$ & $\begin{array}{l}\text { Spain, } \\
\text { Belgium }\end{array}$ & $\begin{array}{l}\text { Public blockchain } \\
\text { (custom protocol, } \\
\text { NRGCoin) }\end{array}$ \\
\hline $\begin{array}{l}\text { Mattila et al. } \\
(2016)\end{array}$ & $\begin{array}{l}\text { Trading electricity } \\
\text { between solar } \\
\text { panel, battery and } \\
\text { appartments }\end{array}$ & $\begin{array}{l}\text { Bilateral or medi- } \\
\text { ated market } \\
\text { between solar } \\
\text { panel and devices } \\
\text { within one building } \\
\text { possible }\end{array}$ & Case study & Finland & n.a. \\
\hline $\begin{array}{l}\text { Aitzhan \& } \\
\text { Svetinovic (2018) }\end{array}$ & $\begin{array}{l}\text { P2P trading of solar } \\
\text { energy and storage } \\
\text { capacity within } \\
\text { microgrid }\end{array}$ & $\begin{array}{l}\text { Auction mecha- } \\
\text { nism for stored } \\
\text { energy, bilateral } \\
\text { market for individ- } \\
\text { ual ad hoc } \\
\text { transactions }\end{array}$ & $\begin{array}{l}\text { Proof of concept } \\
\text { (simulation) }\end{array}$ & $\begin{array}{l}\text { United } \\
\text { Arab } \\
\text { Emirates }\end{array}$ & $\begin{array}{l}\text { Private blockchain } \\
\text { (Bitcoin) }\end{array}$ \\
\hline Hahn et al. (2017) & $\begin{array}{l}\text { Trading between } \\
\text { distributed set of } \\
\text { prosumers, proto- } \\
\text { type using } \\
\text { simulated building } \\
\text { loads and PV array } \\
\text { University campus }\end{array}$ & $\begin{array}{l}\text { Auction mecha- } \\
\text { nism: buyers bid in } \\
\text { one-sided Vickrey } \\
\text { auction }\end{array}$ & $\begin{array}{l}\text { Proof of concept } \\
\text { (on campus demo } \\
\text { with one solar } \\
\text { panel) }\end{array}$ & $\begin{array}{l}\text { US, } \\
\text { China }\end{array}$ & $\begin{array}{l}\text { Private blockchain } \\
\text { (Ethereum) }\end{array}$ \\
\hline Kang et al. (2017) & $\begin{array}{l}\mathrm{P} 2 \mathrm{P} \text { trading of } \\
\text { renewable energy } \\
\text { for plug-in hybrid } \\
\text { electric vehicles } \\
\text { (PHEVs) }\end{array}$ & $\begin{array}{l}\text { Auction mecha- } \\
\text { nism: iterative } \\
\text { double auction }\end{array}$ & $\begin{array}{l}\text { Proof of concept } \\
\text { (simulation of } \\
\text { auction, blockchain } \\
\text { system only } \\
\text { described) }\end{array}$ & $\begin{array}{l}\text { China, } \\
\text { Norway, } \\
\text { Canada }\end{array}$ & $\begin{array}{l}\text { Private blockchain } \\
\text { (custom protocol) }\end{array}$ \\
\hline $\begin{array}{l}\text { Laszka et al. } \\
(2017)\end{array}$ & $\begin{array}{l}\mathrm{P} 2 \mathrm{P} \text { trading of } \\
\text { renewable energy } \\
\text { and storage within } \\
\text { microgrid }\end{array}$ & n.a. & $\begin{array}{l}\text { Conceptual case } \\
\text { study }\end{array}$ & US & $\begin{array}{l}\text { n.a. (Pos blockchain } \\
\text { necessary) }\end{array}$ \\
\hline $\begin{array}{l}\text { Mengelkamp } \\
\text { et al. (2017) }\end{array}$ & $\begin{array}{l}\text { P2P trading of solar } \\
\text { energy within local } \\
\text { microgrid }\end{array}$ & $\begin{array}{l}\text { Auction mecha- } \\
\text { nism: iterative } \\
\text { double auction } \\
\text { with uniform } \\
\text { pricing }\end{array}$ & Field Phase & $\begin{array}{l}\text { Germany, } \\
\text { US }\end{array}$ & $\begin{array}{l}\text { Private blockchain } \\
\text { (Tendermint) }\end{array}$ \\
\hline $\begin{array}{l}\text { Munsing et al. } \\
(2017)\end{array}$ & $\begin{array}{l}\text { Coordination and } \\
\text { payment of DER in } \\
\text { a microgrid, active } \\
\text { control of batteries } \\
\text { and flexible loads } \\
\text { through smart con- } \\
\text { tracts }\end{array}$ & $\begin{array}{l}\text { Distributed optimal } \\
\text { power flow algo- } \\
\text { rithm }\end{array}$ & $\begin{array}{l}\text { Proof of concept } \\
\text { (simulation) }\end{array}$ & US & $\begin{array}{l}\text { Private blockchain } \\
\text { (Ethereum) }\end{array}$ \\
\hline $\begin{array}{l}\text { Sikorski et al. } \\
(2017)\end{array}$ & $\begin{array}{l}\text { M2M exchange of } \\
\text { energy in chemical } \\
\text { industry }\end{array}$ & $\begin{array}{l}\text { Bilateral market: } \\
\text { producers publish } \\
\text { offers, consumer } \\
\text { can choose to } \\
\text { accept or decline }\end{array}$ & $\begin{array}{l}\text { Proof of concept } \\
\text { (prototype of } 2 \text { pro- } \\
\text { sumers and } 1 \\
\text { consumer) }\end{array}$ & $\begin{array}{l}\text { Uk, Sin- } \\
\text { gapore }\end{array}$ & $\begin{array}{l}\text { Private blockchain } \\
\text { (MultiChain) }\end{array}$ \\
\hline Wang et al. (2017) & $\begin{array}{l}\mathrm{P} 2 \mathrm{P} \text { trading of } \\
\text { renewable energy } \\
\text { within microgrid }\end{array}$ & $\begin{array}{l}\text { Auction mecha- } \\
\text { nism: Continuous } \\
\text { double auction } \\
\text { with adaptive } \\
\text { aggressiveness } \\
\text { startegy }\end{array}$ & Case study & $\begin{array}{l}\text { New } \\
\text { Zealand, } \\
\text { Singa- } \\
\text { pore }\end{array}$ & n.a. \\
\hline $\begin{array}{l}\text { Mengelkamp } \\
\text { et al. (2018) }\end{array}$ & $\begin{array}{l}\mathrm{P} 2 \mathrm{P} \text { trading of } \\
\text { renewable energy } \\
\text { within microgrid }\end{array}$ & $\begin{array}{l}\text { Auction mecha- } \\
\text { nism: Iterative } \\
\text { double auction }\end{array}$ & Simulation Study & Germany & Private blockchain \\
\hline
\end{tabular}

Most of the articles present case studies or proofs of concept 
which is very popular in the blockchain community. We searched for whitepapers from those companies that describe a planned ecosystem or prototype.

\section{Results of the literature review}

Tables 1 and 2 provide an overview of the identified relevant articles on peer-to-peer energy exchange using blockchain technology, summarizing the project setting and basic idea described. A key difference to other domains is the early stage of the research field. Most articles either focus on the practical reasoning for a decentralized electricity market, or provide a technical description of a planned system (Kang et al. 2017). Yet, the connection of the two, i.e. a link between technical feasibility and implied practical value to the electricity market, is missing. Most of the articles merely describe a proof of concept that focuses on the technical feasibility of electricity trading, ignoring economic considerations or user-related aspects of creating a novel energy market. Similarly, the whitepapers identified mostly contain conceptual descriptions; in fact, at the time the review was conducted, only a single white paper described a system actually deployed in the field: The Brooklyn Microgrid, the first running exchange in which locally produced power from solar systems is sold within a neighborhood in Brooklyn. It is operated by the company LO3, which has also started to work on other pilot regions in which they implement their exchange platform. The setup of the Brooklyn Microgrid is also documented in the academic literature (Mengelkamp et al. 2017).

Most of the articles reviewed study a mediated and not a bilateral market for the energy exchange. In mediated markets, a market mechanism matches demand and supply on the market as a "virtual" mediator to aggregate information and to define prices. Some of the academic articles (Table 1) name or describe in detail the auction which instantiates the market mechanism, whereas most of the projects presented in whitepapers (Table 2) merely state that various market mechanisms can be implemented on their envisioned

Table 2 Relevant industry articles/whitepapers discussing blockchain-based energy markets

\begin{tabular}{|c|c|c|c|c|c|}
\hline $\begin{array}{l}\text { Project/ } \\
\text { Company }\end{array}$ & Basic idea & Market design & Status & Country & $\begin{array}{l}\text { Blockchain proto- } \\
\text { col }\end{array}$ \\
\hline $\begin{array}{l}\text { Grid+ (Miller et al. } \\
\text { 2017) }\end{array}$ & $\begin{array}{l}\text { P2P trading of } \\
\text { electricity, and } \\
\text { controlling } \\
\text { activators }\end{array}$ & $\begin{array}{l}\text { Different market } \\
\text { models possible }\end{array}$ & $\begin{array}{l}\text { Development } \\
\text { phase }\end{array}$ & US & $\begin{array}{l}\text { Public blockchain } \\
\text { + payment chan- } \\
\text { nels (Ethereum, } \\
\text { Raiden) }\end{array}$ \\
\hline $\begin{array}{l}\text { HivePower } \\
\text { (Rivola et al. 2018) }\end{array}$ & $\begin{array}{l}\text { Platform for P2P } \\
\text { trading of renew- } \\
\text { able energy }\end{array}$ & $\begin{array}{l}\text { Different market } \\
\text { models possible } \\
\text { (e.g. central } \\
\text { optimization) }\end{array}$ & $\begin{array}{l}\text { Development } \\
\text { phase, lab-scale } \\
\text { prototype }\end{array}$ & Switzerland & $\begin{array}{l}\text { Public blockchain } \\
+ \text { state channels } \\
\text { (Ethereum, } \\
\text { custom channels) }\end{array}$ \\
\hline $\begin{array}{l}\text { LO3 Energy } \\
\begin{array}{l}(2017), \quad \text { Men- } \\
\text { gelkamp et al. } \\
(2017)\end{array}\end{array}$ & $\begin{array}{l}\text { P2P trading of } \\
\text { solar energy } \\
\text { within local } \\
\text { community }\end{array}$ & $\begin{array}{l}\text { Auction mecha- } \\
\text { nism: Iterative } \\
\text { double auction }\end{array}$ & $\begin{array}{l}\text { Field phase: local } \\
\text { exchange within } \\
\text { community in } \\
\text { Brooklyn }\end{array}$ & US & $\begin{array}{l}\text { Private } \\
\text { blockchain } \\
\text { (Tendermint) }\end{array}$ \\
\hline $\begin{array}{l}\text { PowerLedger } \\
(2017)\end{array}$ & $\begin{array}{l}\text { P2P trading } \\
\text { of renewable } \\
\text { energy }\end{array}$ & $\begin{array}{l}\text { Different market } \\
\text { models possible } \\
\text { (e.g. central } \\
\text { optimization, } \\
\text { auction) }\end{array}$ & $\begin{array}{l}\text { Development } \\
\text { phase }\end{array}$ & Australia & $\begin{array}{l}\text { Public-private } \\
\text { hybrid } \\
\text { blockchain } \\
\text { (Ethereum, } \\
\text { EcoChain) }\end{array}$ \\
\hline WePower (2017) & $\begin{array}{l}\text { P2P trading } \\
\text { of renewable } \\
\text { energy tokens }\end{array}$ & $\begin{array}{l}\text { Auctions mecha- } \\
\text { nism: not further } \\
\text { defined }\end{array}$ & $\begin{array}{l}\text { Development } \\
\text { phase }\end{array}$ & Gibraltar & $\begin{array}{l}\text { Public blockchain } \\
\text { (Ethereum) }\end{array}$ \\
\hline
\end{tabular}


systems. Concerning the blockchain architecture, it is worth noting that among the articles listed in Table 1 that present a proof of concept or a running prototype, most of the systems are based on private blockchains, while the majority of companies (Table 2) use the public Ethereum blockchain, in most cases in combination with a payment channel solution. The market mechanism is (or can be) implemented in smart contracts on custom blockchain protocols or on the Ethereum protocol. Most of the industry whitepapers define specific tokens, for which they define different proliferation or reward schemes.

Overall, both academic and industry research on decentralized energy exchange enabled by blockchain technology is still in its infancy. The academic articles identified in the literature review present a conceptual case study or a proof of concept without empirical data, mostly focusing of a few selected aspects of the system as a whole. While start-ups in particular were quick to publish whitepapers and conceptual ideas, the majority of those articles provide only vague explanations on the economic viability or the market design. The academic publications we identified give a more refined view of the economic implications of the created peer-to-peer markets; nevertheless, most of the research is still conceptual or based on small simulations. The actual implementation and design of a viable marketplace seems to be more difficult. The early stage of research on blockchain-based markets also becomes apparent when analyzing the arguments brought forward for the use of blockchain technology in the relevant articles identified. The omnipresent and important question of why a blockchain is needed remains mostly unanswered, as many of the benefits of a blockchain system pointed out are of tautological nature such as "trustless" verification or "secure exchange" (Miller et al. 2017; Aitzhan and Svetinovic 2018) and are not put into context of the electricity use case. Many articles merely reproduce generic, unspecific arguments commonly used in the promotion of blockchain technology (Avital et al. 2016). Empirical evidence on the created benefits or arising issues is simply still missing, as most of the identified literature presents conceptual ideas or proofs-of-concept which run in an isolated lab setting.

\section{Field implementation}

To increase empirical knowledge on peer-to-peer energy markets and the benefits of blockchain technology for this application context, our research group has taken an explorative approach and implemented a real-world prototype in the field. We have implemented the first blockchain-based microgrid for solar exchange in Switzerland in order to derive implications for the future design of local markets for renewable energy. Since the start of a test phase in December 2018, the field study has been running in a town in Switzerland with 37 participating households (in which 75 smart meters were installed). Participating households were recruited in cooperation with the local utility provider, and may thus be subject to volunteer selection bias (Tiefenbeck et al. 2019). The majority of these participating households are prosumers, i.e. they own their own solar panel, and they can now trade their solar energy with other participants using the blockchain system. For the study duration of one year, participants of the pilot project are charged for their electricity according to the outcomes of the local market. The local utility provider serves as back up securing energy balance in the microgrid at all times. As the existing literature on blockchain-based energy exchange provided little details on appropriate allocation and pricing rules for matching supply and demand on the local market, we drew on economic theory of market design taking into account the specific requirements 
of the energy domain. Likewise, the distributed software system was designed to meet these requirements in the best possible manner. In the following, we present the market design selected and the technical implementation in detail. This description partially corresponds to our ArXiv preprint (Ableitner et al. 2019).

\section{Market design}

In order to create a successful peer-to-peer market for electricity in line with the overall objective of promoting sustainability, there should be incentives for local consumption of locally generated electricity. Consequently, prices should reflect the local availability of renewable electricity. The market design describes the way in which prices are determined and local electricity is distributed within the community and should be defined with the aim to meet these overall project goals (Ketter et al. 2013).

The importance of an appropriate market design for electricity distribution is illustrated by the infamous example of the breakdown of the California electricity market in 2001, which caused unforeseen price jumps and even led to outages (Borenstein et al. 2002). In general, there are two alternatives for determining prices and the allocation of electricity: a) Running an algorithm which calculates prices relative to the availability of local resources and distributes the available energy randomly to the community members; b) Running an auction mechanism that allows the participants to state price limits for which they are willing to buy or sell electricity with-in the local grid. Most existing electricity markets are governed by auction mechanisms, and are also suggested in the identified literature on blockchain-based electricity trading (Ketter et al. 2013; Rosen and Madlener 2013). That means that participants express their preferences in bids which contain a price and a commodity or quantity of commodities they wish to buy. All bids are collected in an order book and at distinct times, these orders are matched to form trades between the participants according to specific auction rules. These auction rules have a strategic impact on the incentives market participants face when formulating their bids in order to maximize the expected benefits (Klemperer 2002). There are numerous research studies on auction mechanisms and their implications for economic efficiency and price development (Rosen and Madlener 2013; Fabra et al. 2002). However, those existing markets are wholesale markets, in which professional firms interact and not private households, as is the case in a peer-to-peer energy market. It is a fundamental shift that households, which are currently merely price-takers in a retail market, change their roles to active prosumers and consumers who influence electricity sourcing themselves.

Based on the related literature (Mengelkamp et al. 2017; Wang et al. 2017; Rassenti et al. 2003), we have identified a double auction with discriminative pricing as the most suitable market mechanism for electricity exchange. The smart meters of both consumers and prosumers send bids containing the price limit determined by the individual household and the electricity demand or supply measured by the smart meters. An order book collects all bids during an interval of $15 \mathrm{~min}$ and orders them by price. After this period, orders are matched accordingly and the resulting trade is priced at the mid point of these two bids. Discriminative pricing thus means that for each trade, the price for each trade is derived individuall as the mean between the respective buyer's and seller's price bid. This auction is run iteratively every $15 \mathrm{~min}$, which means that the market is cleared and trades are allocated in this frequency. 
A key decision for the market design in this domain was to create an auction in which all participants have the possibility to influence the prices for which they buy or sell electricity. While we do not expect participants to adapt their prices regularly in the long run, we do believe this is a unique chance to elicit price preferences for local, renewable energy from individuals in a real setting. To date, some survey-based studies have elicited individuals' willingness to pay for green or local electricity or assessed their intention to invest in renewable energies (Ecker et al. 2018; Tabi et al. 2014). Yet, to the best of our knowledge, this is the first study that allows individuals to actually influence the true prices they will pay.

We have deployed the double auction on the application level of the blockchain system which will be described in the following section. The double auction was implemented in TypeScript and is integrated into the blockchain platform. The implementation integrates the local utility company in the market by assigning all excess bids which cannot be filled with local supply or demand to the utility provider at existing tariffs, to secure energy balance at all times. The auction algorithm is run automatically every 15 min to clear the market. To enable users to set their desired limit prices for the auction, we have implemented a price slider in a web application we have created for this project which will be discussed in further articles.

\section{System architecture}

To ensure mutual validation of the correctness of transactions, computation, and auction settlement, we chose a decentralized blockchain-based approach. Consensus over the current state of the system is negotiated between the validating nodes using the Tendermint consensus protocol (Tendermint). The Tendermint consensus protocol allows for high adaptability due to its Application Blockchain Interface (ABCI) universally available to any programming language. In addition, Tendermint offers a high amount of flexibility and customizability in order to adjust to particular application requirements such as: the reduction of communication, creation of empty blocks, and time delay between blocks.

The availability of the platform and its applications is vital to its operation: A centralized platform architecture requires a permanently available server. In contrast, the Byzantinefault-tolerance property of the Tendermint protocol increases the resiliency of the system and allows nodes to continue safe operation as long as less than $2 / 3$ of the nodes are offline or malicious. Fault tolerant behavior is especially useful for nodes that control flexible assets, which in turn may be used in the future to curtail solar energy or demand peaks to reduce loads and over-voltages in the distribution grid.

The permissioned blockchain network consists of three different types of participants: The core of the platform are the validator nodes (full nodes), which are represented by the producers and the utility company. The user base is represented by consumer nodes, which are clients (light nodes) of the producers, who delegate their trust to the validators and do not propose new blocks on their own. The authority to create and sign new blocks within the proof-of-stake consensus mechanism of the platform is assigned to the prosumer participants and the utility company. The decision to trust prosumers in the systems is based on the rationale that they have already made an investment in the system (in the form of a PV system). While the current distribution of voting power is equal for every active validating node, future enhancements of the platform include an active staking mechanism to incorporate solar investment size while maintaining a valid 
equilibrium between the nodes. Overall, our system thus comprises of 75 nodes installed on the 75 smart meters in the field. The market application is built as a smart contract on top of the Tendermint blockchain. The functionality of the system can be split up into four main parts (a graphical illustration of the system architecture is provided in (Ableitner et al. 2019)):

- Data Acquisition: Smart meter and read-out application

- Data Management: Agent and client application to process acquired data, issue transactions and manage signatures

- Data Processing: Full / light node for execution and validation of platform applications and subscription to updates

- Data Provision: Making data available for applications and user interfaces

Data Acquisition Even though data acquisition is separate from the blockchain-based functionality, it is part of the chain of trust. Measured data is the basis for settlements in the market application. In addition to being responsible for the data acquisition, the smart meters (Smart-Pis) host the P2P market application (i.e. the market application runs on the smart meter) as well as the Data Management and Processing functionalities of the platform.

Data Management The management of actions, such as sending out buy or sell orders or updating price preferences based on the acquired data, is handled by the agent software module. This module performs the coordination of actions on the end-users' side of the system. While synchronizing with the blockchain and its regularly published blocks, this module contains information about the user's preferences, such as sell and buy prices, and follows a strategy according to its collected information. The module issues buy or sell orders based on the current consumption and production, which are the inputs to the market mechanism. Transactions include the sender's public key as well the sender's address, similar to values typically found in blockchain transactions. By using the SHA256 hash of a user's public key as an address, we enable transactions to have a unique identifier while preserving pseudonymous privacy of users.

Data Processing Blocks are created periodically. Checking all blocks via the block handler - a self-triggered mechanism within the platform - allows for automated actions (e.g. periodic clearing) as required by the market application. Incoming transactions are processed by the transaction handler according to their receiver and payload. When verifying the validity of a transaction, the nodes deserialize its content, derive the address from its contained public key, and compare it with the given address. According to the receiver address and the data contained in the payload field of the transaction, the transaction handler forwards the information to the respective handlers of the application modules. In the case of the market application, the arrival of a transaction containing a buy or sell order triggers the addition of a new bid.

Data Provision In order to offer services to the end-users, such as comprehensible information about consumption and production via external applications, a block explorer is available and provides a queryable API to the system to access transactions, trades and payments.

Prior to the field deployment of the system, all system components were tested extensively in the lab to ensure reliable communication and validity of the collected data. The rollout of the Smart-Pis required more coordination with external service providers than 
anticipated. Eventually, the team succeeded thanks to the modern existing infrastructure and the support of the local utility company, and by involving additional service providers for internet communication and smart meter billing services. Furthermore, the infrastructure described above was deployed in parallel to the households' existing smart meters. The redundancy in the infrastructure allows regular validity checks of the measurement data. Since the deployment of the system, both automated and manual checks are performed on a regular basis to ensure the reliability of the system and validity of the data collected.

\section{Conclusion \& next steps}

The electricity sector is currently undergoing a paradigm shift that involves the integration of an increasing share of volatile renewable energies and a decentralization of power markets. High hopes are put in blockchain technology as one solution to enable the decentralization of the energy market by facilitating the exchange of electricity directly between individual producers of renewable energy and consumers (Basden and Cottrell 2017; Hasse et al. 2016; Kastrati and Weissbart 2016; Morstyn et al. 2018).

However, the results of our literature review (covering both academic and industry research) lead us to the conclusion that except for few exceptions, most projects are still far from implementing a system in the field. The results indicate that most articles describe conceptual studies or a proof of concept and that empirical data from the field is still missing. Moreover, most articles only touch upon the economic implications of the created peer-to-peer market on a very high level, lacking a solid explanation of the added value blockchain technology brings to the system as a whole. This is due to the fact that most projects are at a stage in which they only present concepts or develop first proofs of concept in the lab, but are not yet rolling out solutions in the field with human participants.

In this research-in-progress article, we present the first field study on a blockchainbased electricity market in Switzerland. We contribute to the knowledge on blockchain technology in the energy by presenting the system design and background on existing projects on blockchain-based electricity markets. We developed and implemented a realworld prototype of a decentralized energy market in the field. This market will be running for the duration of one year (until the end of 2019), and we will analyze and evaluate the resulting data to evaluate the system design, market efficiency and performance of the blockchain system in the field. With the system presented here, we will generate empirical data in a real blockchain-based electricity market, thus providing scientific evidence gathered in the field on this topic. There is vast potential for further research regarding the examination of the technical system design and its interplay with the economics of decentralized markets in detail. These efforts will be valuable in order to create successful peer-to-peer energy markets, to advance the decentralization of the electricity market on a large scale, and ultimately, to secure a reliable, affordable, and sustainable electricity supply in the future. 


\section{Authors' contributions}

AW conducted the literature review, drafted large parts of the article and implemented the market application described. AM implemented large parts of the system described and drafted parts of the article. LA and SS implemented parts of the system described. VT and FW enabled and oversaw the implementation of the study. VT and SS edited the article. All authors read and approved the final manuscript.

\section{Funding}

This research project is supported within the flagship program by the Swiss Federal Office of Energy.

\section{Competing interests}

The authors declare that they have no competing interests.

\section{Author details}

${ }^{1}$ ETH Zürich, Zürich, Switzerland. ${ }^{2}$ University of St. Gallen, St. Gallen, Switzerland.

Published: 23 September 2019

\section{References}

Ableitner L, Meeuw A, Schopfer S, Tiefenbeck V, Wortmann F, Wörner A (2019) Quartierstrom-implementation of a real world prosumer centric local energy market in walenstadt, switzerland. arXiv preprint. arXiv:1905.07242. http://export. arxiv.org/pdf/1905.07242

Aitzhan NZ, Svetinovic D (2018) Security and privacy in decentralized energy trading through multi-signatures, blockchain and anonymous messaging streams. IEEE Transactions on Dependable and Secure Computing 15(5):840-852

Andoni M, Robu V, Flynn D, Abram S, Geach D, Jenkins D, McCallum P, Peacock A (2019) Blockchain technology in the energy sector: A systematic review of challenges and opportunities. Renewable and Sustainable Energy Reviews 100:143-174

Avital M, Beck R, King J, Rossi M, Teigland R (2016) Jumping on the blockchain bandwagon: Lessons of the past and outlook to the future

Basden J, Cottrell M (2017) How utilities are using blockchain to modernize the grid. Harvard Business Review 23:1-8

Beck R, Avital M, Rossi M, Thatcher JB (2017) Blockchain technology in business and information systems research. Business \& Information Systems Engineering 59(6):381-384

Borenstein S, Bushnell JB, Wolak FA (2002) Measuring market inefficiencies in california's restructured wholesale electricity market. The American Economic Review 92(5):1376-1405

Ecker F, Spada H, Hahnel U (2018) Independence without control: Autarky outperforms autonomy benefits in the adoption of private energy storage systems. Energy Policy 122(July):214-228

Fabra N, Von der Fehr N-H, Harbord D (2002) Modeling electricity auctions. The Electricity Journal 15(7):72-81

Green J, Newman P (2017) Citizen utilities: The emerging power paradigm. Energy Policy 105:283-293

Hahn A, Singh R, Liu C-C, Chen S (2017) Smart contract-based campus demonstration of decentralized transactive energy auctions. In: IEEE Power \& Energy Society Innovative Smart Grid Technologies Conference (ISGT). IEEE

Halu A, Scala A, Khiyami A, Gonzalez MC (2016) Data-driven modeling of solar-powered urban microgrids. Science Advances 2(1):1500700

Hasse F, von Perfall A, Hillebrand T, Smole E, Lay L, Charlet M (2016) Blockchain-an opportunity for energy producers and consumers. PwC Global Power \& Utilities: $1-45$

Hentschel M, Ketter W, Collins J (2018) Renewable energy cooperatives: Facilitating the energy transition at the Port of Rotterdam. Energy Policy 121:61-69

Kang J, Yu R, Huang X, Maharjan S, Zhang Y, Hossain E (2017) Enabling localized peer-to-peer electricity trading among plug-in hybrid electric vehicles using consortium blockchains. IEEE Transactions on Industrial Informatics 13(6):3154-3164

Kastrati G, Weissbart C (2016) Kurz zum klima: Blockchain-potenziale und herausforderungen für den strommarkt. ifo Schnelldienst 69(23):74-77

Ketter W, Collins J, Reddy P (2013) Power TAC: A competitive economic simulation of the smart grid. Energy Economics 39:262-270

Khalilpour R, Vassallo A (2015) Leaving the grid: An ambition or a real choice? Energy Policy 82:207-221

Klemperer P (2002) What Really Matters in Auction Design. Journal of Economic Perspectives 16(1):169-189

Laszka A, Dubey A, Walker M, Schmidt D (2017) Providing privacy, safety, and security in iot-based transactive energy systems using distributed ledgers. In: Proceedings of the Seventh International Conference on the Internet of Things IOT 17. ACM Press

LO3 Energy (2017) Exergy - Building a robust value mechanism to facilitate transactive energy. Whitepaper

Malinova K (2016) Market design for trading with blockchain technology. SSRN Electronic Journal 2785626

Mattila J, Seppala T, Naucler C, Stahl R, Tikkanen M, Baadenlid A, Seppala J, et al. (2016) Industrial blockchain platforms: An exercise in use case development in the energy industry. Technical report, The Research Institute of the Finnish Economy

Meeuw A, Schopfer S, Ryder B, Wortmann F (2018) Lokalpower: Enabling local energy markets with user-driven engagement. In: Extended Abstracts of the 2018 CHI Conference on Human Factors in Computing Systems. CHI EA '18. ACM, Montreal. pp 613-16136. https://www.alexandria.unisg.ch/254083/

Mengelkamp E, Gärttner J, Rock K, Kessler S, Orsini L, Weinhardt C (2017) Designing microgrid energy markets: A case study: The brooklyn microgrid. Applied Energy 210:870-880

Mengelkamp E, Gärttner J, Weinhardt C (2018) Decentralizing energy systems through local energy markets: The lamp project. Multikonferenz Wirtschaftsinformatik:924-930

Miller A, Kreder K, D'Agostino M, Pop C, Epstein R, Chen Y, Berarducci P, Walters M (2017) GridPlus. Whitepaper 
Mihaylov M, Jurado S, Avellana N, Van Moffaert K, de Abril IM, Nowé A (2014) Nrgcoin: Virtual currency for trading of renewable energy in smart grids. In: 11th International Conference on the European Energy Market (EEM14). IEEE. pp 1-6

Mihaylov M, Jurado S, Van Moffaert K, Avellana N, Nowe A (2014) Nrg-x-change-a novel mechanism for trading of renewable energy in smart grids. In: Smartgreens. pp 101-106

Montemayor L, Boersma T, van Dorp T (2018) Comprehensive guide to companies involved in blockchain and energy. Blockchain Business

Morstyn T, Farrell N, Darby SJ, McCulloch MD (2018) Using peer-to-peer energy-trading platforms to incentivize prosumers to form federated power plants. Nature Energy 3(2):94-101

Munsing E, Mather J, Moura S (2017) Blockchains for decentralized optimization of energy resources in microgrid networks. In: IEEE Conference on Control Technology and Applications (CCTA). IEEE

Notheisen B, Hawlitschek F, Weinhardt C (2017) Breaking down the blockchain hype-towards a blockchain market engineering approach

PowerLedger (2017) PowerLedger. Whitepaper

Ramchurn SD, Vytelingum P, Rogers A, Jennings NR (2012) Putting the smarts into the smart grid. Communications of the ACM 55(4):86

Rassenti SJ, Smith VL, Wilson BJ (2003) Discriminatory Price Auctions in Electricity Markets: Low Volatility at the Expense of High Price Levels. Journal of regulatory Economics 23(2):109-123

Rivola D, Medici V, Nespoli L, Corbellini G, Strepparava D (2018) Hive Power. Whitepaper

Rosen C, Madlener R (2013) An auction design for local reserve energy markets. Decision Support Systems 56:168-179

Schlegel M, Zavolokina L, Schwabe G (2018) Blockchain technologies from the consumers perspective: What is there and why should who care? In: proceedings of the Hawaii International Conference on Systems Sciences (HICSS). Hawaii International Conference on System Sciences

Sikorski JJ, Haughton J, Kraft M (2017) Blockchain technology in the chemical industry: Machine-to-machine electricity market. Applied Energy 195:234-246

Tabi A, Hille SL, Wüstenhagen R (2014) What makes people seal the green power deal?A customer segmentation based on choice experiment in germany. Ecological Economics 107:206-215

Tendermint Tendermint Documentation. https://tendermint.com/docs/. Accessed 30 Mar 2019

Tiefenbeck V (2017) Bring behaviour into the digital transformation. Nat Energy 2(6)

Tiefenbeck V, Wörner A, Schöb S, Fleisch E, Staake T (2019) Real-time feedback promotes energy conservation in the absence of volunteer selection bias and monetary incentives. Nature Energy 4(1):35

Vona F, Nicolli F (2014) Energy market liberalization and renewable energy policies in oecd countries. Barcelona Institute of Economics, Working Paper

Wang J, Wang Q, Zhou N, Chi Y (2017) A novel electricity transaction mode of microgrids based on blockchain and continuous double auction. Energies 10(12):1971

Webster J, Watson RT (2002) Analyzing the past to prepare for the future: Writing a literature review. Quarterly, MIS 26(2):xiii-xxiii

WePower (2017) WePower. Whitepaper

\section{Publisher's Note}

Springer Nature remains neutral with regard to jurisdictional claims in published maps and institutional affiliations.

\section{Submit your manuscript to a SpringerOpen ${ }^{\circ}$ journal and benefit from:}

- Convenient online submission

- Rigorous peer review

- Immediate publication on acceptance

- Open access: articles freely available online

- High visibility within the field

- Retaining the copyright to your article

Submit your next manuscript at $>$ springeropen.com 